\title{
Effect of Fluoride Ions on Ti6Al4V Alloy Passivation in Lactated Ringer's Serum
}

\author{
Anelise M. Schmidt, Denise S. Azambuja* \\ Laboratory of Electrochemistry, Institute of Chemistry, \\ Federal University of Rio Grande do Sul \\ Av. Bento Gonçalves 9500, 91501-970, Porto Alegre - RS, Brazil
}

Received: July 4, 2002; Revised: January 20, 2003

\begin{abstract}
The corrosive behavior of $\mathrm{Ti}$ and its alloys in fluoride media is well known. Based on electrochemical studies, this paper describes the effect of fluoride ions on the passive behavior of Ti6Al4V alloy in lactated Ringer's serum. The open circuit potential of the alloy in the serum, which lies in the passive region of $\mathrm{TiO}_{2}$, shifts to more negative values as fluoride ions are added. The voltammogram obtained in the serum presents an active-passive behavior close to $-0.2 \mathrm{~V}$ (SCE) that changes with the presence of fluoride ions, evidencing higher anodic currents. Electrochemical impedance spectroscopy plots obtained at OCP after varying immersion times in the serum display an almost capacitive behavior and the polarization resistance becomes enhanced after 7 days. With the addition of fluoride ions, the film's resistance decreases, but a stable protective layer develops after 7 days of immersion time, indicating the film's repair.
\end{abstract}

Keyword: titanium alloy, serum, fluoride

\section{Introduction}

Titanium is one of the most important materials for biomedical and dental implants due to its high corrosion resistance in many systems. It is well known that $\mathrm{NaF}$ and other fluoride compounds are materials commonly employed in dental treatments. In fact, most brands of toothpaste contain a fluoride concentration of about $1 \%$, while concentrations of approximately $2 \%$ are used to remove stains from enamel. Despite the benefits offered by fluoride, however, its infiltration into dental implants may cause Ti corrosive attack. Several authors ${ }^{1-4}$ have studied the breakdown of passive films on $\mathrm{Ti}$ in the presence of halide. According to Raetzer-Sheibe ${ }^{1}$, there is a tendency for chemisorption of halide ions on the oxide/electrolyte interface, which may explain the change in the repassivation behavior of Ti6Al4V in $1.0 \mathrm{~mol} / \mathrm{l} \mathrm{NaF}$, since fluoride ions are strongly adsorbed on $\mathrm{TiO}_{2}$ surface. $\mathrm{Beck}^{2,3}$, who determined the pitting potential for titanium in $\mathrm{Br}^{-}, \mathrm{Cl}^{-}$and $\mathrm{I}^{-}$ solutions, observed the propagation of pits on Ti foils in the presence of bromide. According to Beck, $\mathrm{Ti}^{+3}$ was the dominant dissolved species at a pH below 1.3 close to a corrod- ing pit exposed to a neutral chloride solution. Ramires and Guastaldi ${ }^{4}$ demonstrated that pitting did not occur on Ti6Al4V alloy in $0.15 \mathrm{~mol} / \mathrm{l} \mathrm{NaCl}$ without film breakdown after polarization up to $3.0 \mathrm{~V}$ (SCE).

Many authors have studied the electrochemical behavior of Ti-based alloys for implants in simulated biofluid media. Gonzalez and Mirza-Rosca ${ }^{5}$ investigated the behavior of several Ti alloys in Ringer solution, using EIS, and found a capacitive system for Ti7Al4.5V with the formation of a thin passive film. Pan et al. ${ }^{6}$ proposed a double layer model for the film formed on $\mathrm{Ti}$ alloys of implants in a phosphate buffer solution, with a thin compact inner layer and a porous outer layer. According to Ciolac et al. ${ }^{7}$, the corrosion resistance of Ti-Al-Mo alloys in Ringer solution depends on the film's composition, the degree of hydration and the $\mathrm{pH}$ of the solution. These authors used a Ringer's solution whose $\mathrm{pH}$ varied in range with lactic acid but contained no added fluoride ions. Ti-based alloys present spontaneous passivity in deaerated lactated Ringer's solution at $37^{\circ} \mathrm{C}^{8}$. XPS investigations of Ti6Al4V in a saline pseudo-physiological solution indicate that the passive film consists mainly of $\mathrm{TiO}_{2}, \mathrm{Al}_{2} \mathrm{O}_{3}$ and small amounts of $\mathrm{V}$ oxide, and 
that the biocompatibility of this alloy diminishes after lengthy application in a living body ${ }^{9}$. Fernandez et al. ${ }^{10} \mathrm{ob}-$ served that the growth rate of the Ti oxide layer is affected by fluoride anions when Ti is immersed in synthetic saliva having different compositions and $6.5<\mathrm{pH}<7$. Blisters caused by internal stresses have been detected by SEM (scanning electron microscopy) in the oxide layer in the presence of fluoride. On the other hand, Reclaru and Meyer ${ }^{11}$ have shown that crevices and pitting occur in Ti alloys of dental implants in a NaCl-containing electrolyte with fluoride at $\mathrm{pH}<3.5$. A general survey of the literature ostensibly indicated that the corrosion of Ti implants in fluoride media is strongly associated with the formation of halide complexes and the medium's pH. However, to the best of our knowledge, no investigations have yet focused on the influence of fluoride ions on the stability of the oxide film formed on the Ti surface in Ringer's lactate solutions.

The aim of this study, therefore, was to investigate the effect of fluoride ions on the electrochemical behavior of Ti6Al4V alloy in lactated Ringer's serum by means of open circuit potential (OCP) measurements, cyclic voltammetry (CV) and electrochemical impedance spectroscopy (EIS).

\section{Experimental}

A conventional three-electrode cell was used for the electrochemical experiments, for which the working electrode was a Ti-6Al-4V rod (composition in Table 1) inserted into a Teflon holder, with an exposed geometric area of $0.0314 \mathrm{~cm}^{2}$. This electrode was polished with 600 and 1000 emery paper, degreased with acetone and rinsed in pure water before each measurement. The reference electrode was the saturated calomel electrode (SCE), to which all the potentials were referred, and a Pt wire was used as the counter electrode.

Electrochemical measurements were made using lactated Ringer's serum with a pH of 6.5 to simulate a physiological medium, whose composition is given in Table 2, and containing $0.1 \mathrm{~mol} / \mathrm{l} \mathrm{NaF}$ under environmental conditions.

Electrochemical impedance spectra were obtained using an Autolab PGSTAT-30 device in a frequency range of $100 \mathrm{kHz}$ to $10 \mathrm{MHz}$ and an amplitude of $10 \mathrm{mV}$, while

Table 1. Composition/wt $\%$ of Ti6Al4V alloy (Brodene-Dahla).

\begin{tabular}{ccccccc}
\hline $\mathrm{N}$ & $\mathrm{C}$ & $\mathrm{H}$ & $\mathrm{Fe}$ & $\mathrm{O}$ & $\mathrm{Al}$ & $\mathrm{V}$ \\
\hline 0.05 & 0.10 & 0.0125 & 0.40 & 0.20 & $5.5-6.5$ & $3.5-4.5$ \\
\hline
\end{tabular}

Table 2. Composition of lactated Ringer's serum (0.1 1).

\begin{tabular}{lccc}
\hline $\mathrm{NaCl}$ & $\mathrm{KCl}$ & $\mathrm{CaCl}_{2}$ & Na-lactate \\
\hline $0.6 \mathrm{~g}$ & $0.03 \mathrm{~g}$ & $0.02 \mathrm{~g}$ & $0.3 \mathrm{~g}$ \\
\hline
\end{tabular}

voltammetric curves were obtained using the same device. Each experiment was repeated three times to ensure reproducibility.

\section{Results and Discussion}

Figure 1 presents the OCP variation according to the alloy's immersion time in the serum, with and without fluoride. The OCP in the serum was found to increase during the first $5 \mathrm{~min}$ and was located in the passive region ${ }^{12}$ in relation to an oxide film formed on the metal surface. The addition of fluoride ions caused the OCP to shift to more negative values, although the OCP remained in the passive region after one hour of immersion. Increasing the immersion time to one week caused only slight variations in the OCP, indicating that passive oxide film growth occurred even in the presence of fluoride (Table 3). Ciolac et al. ${ }^{7}$ observed OCP values close to $-0,3 \mathrm{~V} \times \mathrm{SCE}$ in Ti-Al-Mo alloys in Ringer solution with a $6.38 \mathrm{pH}$ at $37^{\circ} \mathrm{C}$, relating to the passive region of $\mathrm{TiO}_{2}$, according to Pourbaix ${ }^{12}$. Reclaru and Meyer ${ }^{11}$ showed that the OCP of Ti in Fusayama saliva returned to positive values after $100 \mathrm{~h}$ of immersion, even in the presence of fluoride. According to Fernandez et al. ${ }^{10}$, when fluoride ions are added to a synthetic saliva containing chloride with a $6.5 \mathrm{pH}$, the OCP of Ti remains unstable at low values $(-0.3 \mathrm{~V} \times \mathrm{SCE})$. SEM micrographs of Ti4Al4V

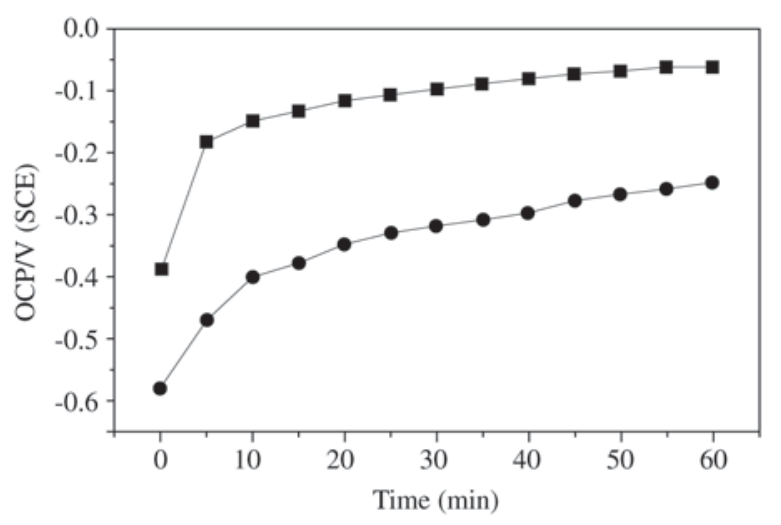

Figure 1. OCP variation of Ti6Al4V alloy according to immersion time in lactated Ringer's serum $(\boldsymbol{\square})$ and with $0.1 \mathrm{~mol} / \mathrm{l}(\bullet)$.

Table 3. OCP/V(SCE) of Ti6Al4V in lactated Ringer serum.

\begin{tabular}{ccc}
\hline Days & Without fluoride & With fluoride \\
\hline 1 & -0.153 & -0.288 \\
2 & -0.130 & -0.242 \\
3 & -0.124 & -0.229 \\
4 & -0.110 & -0.210 \\
7 & -0.090 & -0.206 \\
\hline
\end{tabular}


in $\mathrm{NaCl} 1 \%$ and $\mathrm{NaCl} 1 \%+\mathrm{NaF} 0.1 \%$ obtained by Jesuino et al. ${ }^{13}$ after 4 months of immersion showed a pitting process caused by the film's dissolution due to the complexing action of the halides. Schiff et al. ${ }^{14}$ found that the OCP of Ti6Al4V in a fluoridated saliva with a $\mathrm{pH}$ of 5.3 reached $0.3 \mathrm{~V}$ (SCE) after $24 \mathrm{~h}$ of exposure, suggesting a decrease in the passive film's resistance.

The voltammetric curve obtained for the alloy in the serum, between -1.0 and $4.0 \mathrm{~V}$, with $v=0.05 \mathrm{~V} / \mathrm{s}$ (see Fig. 2), shows an anodic peak at $\sim-0.25 \mathrm{~V}$ followed by a region with a practically constant current, indicating the film's growth. Other authors found the same behavior in Ti6Al4V alloy in chloride media. Ramires and Guastaldi ${ }^{4}$ observed a wide region of current stability, ranging from 0 to $1.5 \mathrm{~V} \times \mathrm{SCE}$, associated with $\mathrm{TiO}_{2}$ film growth. According to $\mathrm{Yu}$ and Scully ${ }^{8}$, Ti6Al4V alloy was spontaneously passive in a deaerated Ringer's solution at $37{ }^{\circ} \mathrm{C}$, which was consistent with the stability of $\mathrm{TiO}_{2}$. The voltammetric curve obtained in the presence of fluoride indicated the same anodic peak, but the anodic currents increased, indicating fluoride ion adsorption on the passive film, which caused its dissolution and/or the formation of a porous layer. Schiff ${ }^{14}$ obtained a similar voltammogram for Ti6Al4V in fluoridated saliva with a $5.3 \mathrm{pH}$. Polarization curves obtained by Fernandez et al. ${ }^{10}$ for $\mathrm{Ti}$ in a synthetic saliva, $\mathrm{pH} 6.5$, containing different fluoride concentrations, showed a current density increase at 0.4 and $0.2 \mathrm{~V} \times \mathrm{SCE}$ for $0.02 \mathrm{M}$ and $0.2 \mathrm{M} \mathrm{NaF}$, respectively, relating to the film's breakdown. Reclaru and Meyer ${ }^{11}$ obtained the same results for Ti in a solution of $\mathrm{NaCl} 1 \%$ and $\mathrm{KF} 0.1 \%$ with $\mathrm{pH} 6.15$, in which the anodic current was higher than in the absence of fluoride. The polarization curve obtained by these authors showed a breakdown potential around $0.2 \mathrm{~V} \times \mathrm{SCE}$, but no corrosion was observed in this range of $\mathrm{pH}$ (6.15 to 3.5). The complexing effect of fluoride ion is well known. According to Reclaru and Meyer ${ }^{11}$, the halide complexes $\left[\mathrm{TiCl}_{6}\right]^{\mathrm{n}}$ and $\left[\mathrm{TiF}_{6}\right]^{\mathrm{n}}$ are known to be molecular species able to form soluble salts with alkaline metals, which explains the dissolution of $\mathrm{Ti}$ in the presence of fluoride. Furthermore, a fluoride ion concentration of $20 \mathrm{ppm}$ at $6<\mathrm{pH}<7$ suffices to produce localized corrosion on $\mathrm{Ti}^{15}$.

The EIS spectra for the alloy were obtained at the open circuit potential over various immersion times in the serum, both with and without the addition of $0.1 \mathrm{~mol} / \mathrm{l}$ of $\mathrm{NaF}$. The Nyquist plots after one hour of exposure in both the solutions (Fig. 3) show an almost capacitive behavior, with a decrease of the total impedance and a depression of the capacitive loop in the fluoride media, indicating the formation of a more porous film.

Increasing the immersion time caused the Bode plots of the alloy immersed in the serum (Fig. 4) from 1 to 7 days to display enhanced polarization resistance and a maximum phase angle close to $80^{\circ}$, indicating greater stability of the oxide film. These results are consistent with others obtained earlier in biological enviroments ${ }^{5,6}$. As illustrated in Fig. 5, the resistance of film immersed in fluoride containing serum increased after 7 days' immersion in this medium. The diagrams show two overlapping time constants in the middle and low frequency range, which may relate to an adsorption process on the electrode's surface ${ }^{18}$.

A fitting of the experimental data allows us to propose

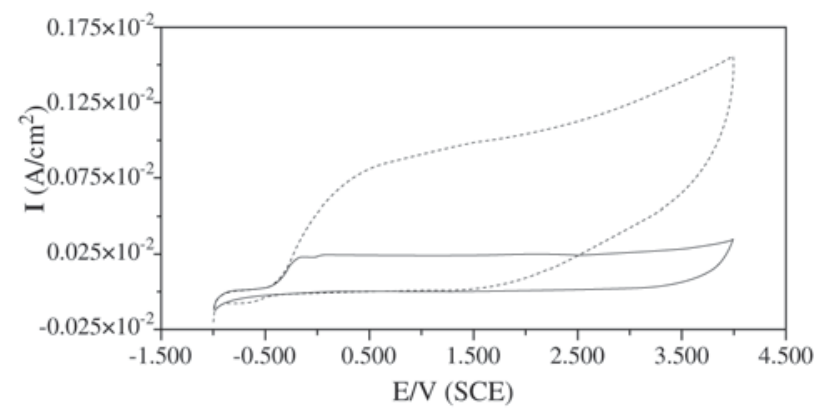

Figure 2. Voltammetric curves obtained for Ti6Al4V from -1.0 to $4.0 \mathrm{~V}$, with $v=0.05 \mathrm{~V} / \mathrm{s}$, in the serum (solid line) and in the presence of fluoride (dotted line).

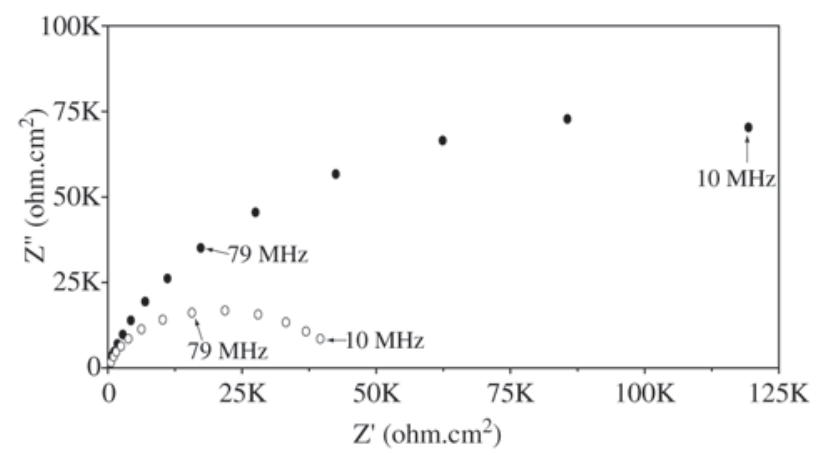

Figure 3. Nyquist plots obtained for the alloy at OCP after one hour's immersion in the serum $(\bullet)$ and with $0.1 \mathrm{~mol} / 1 \mathrm{NaF}(\mathrm{O})$.

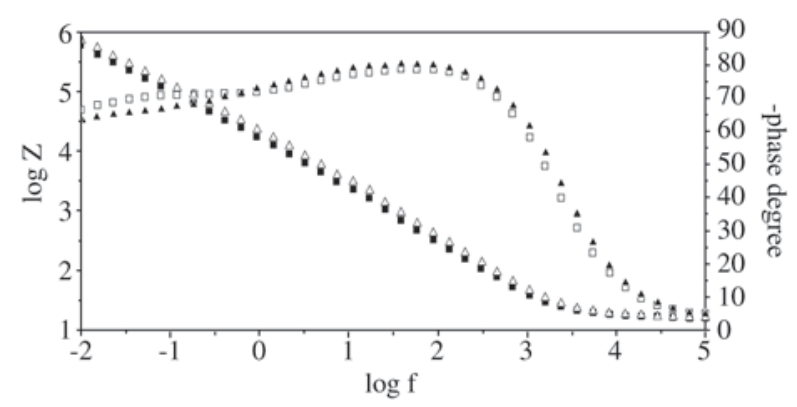

Figure 4. Bode plots obtained for Ti6Al4V at OCP in the serum after 1 day $(\square)$ and 7 days $(\Delta \triangle)$ of immersion. 
an equivalent electrical circuit (EC), based on a two-layer oxide film model consisting of a more compact inner layer and a porous outer layer, which is congruent with several studies $^{6,16,17}$. Figure 6 shows a comparison of the measured and fitted Bode plots of the alloy obtained after 3 days' immersion in fluoride containing serum. The proposed circuit,

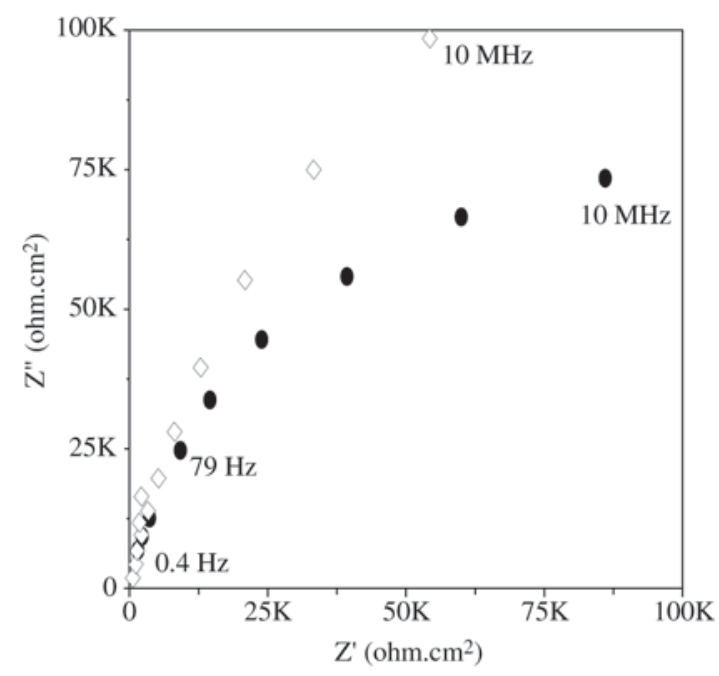

Figure 5. Nyquist plots obtained for the alloy at OCP in fluoride containing serum after 1 day $(\bullet)$ and 7 days $(\diamond)$ of immersion.

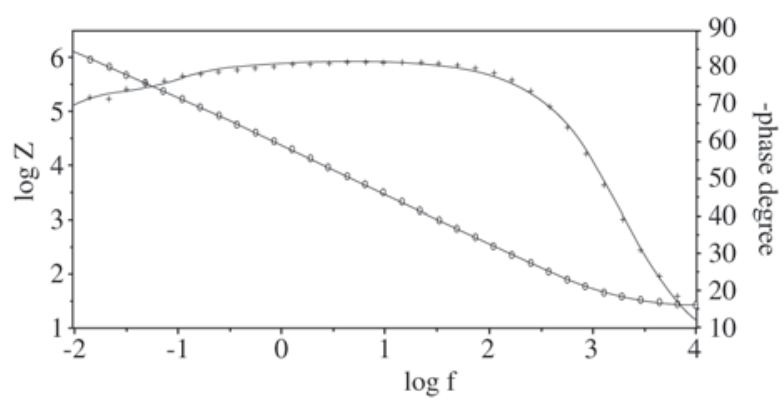

Figure 6. Experimental and fitted (solid line) Bode plots obtained for Ti6Al4V at OCP after 3 days of immersion in fluoride containing serum. see Fig. 7, includes the solution's resistance $\left(\mathrm{R}_{3}\right)$, the inner layer's capacitance $\left(C_{1}\right)$, the resistance $\left(R_{1}\right)$ and the outer layer's resistance $\left(R_{2}\right)$, as well as a constant phase element (CPE) that replaces the outer layer's capacitance. The CPE takes into account the phenomena involved in the surface roughness and diffusion processes ${ }^{20}$.

Table 4 presents the values of the parameters used in the simulated circuits. These data merit some comments. An increase in exposure time causes the barrier film to become more protective, which may be attributed to thickening of the oxide film and to sealing of the outer porous layer ${ }^{6}$. As can be seen, after 7 days of immersion, the alloy shows decreased capacitance, indicating the formation of a more compact film. On the other hand, in the presence of fluoride, the film's resistance after 7 days of exposure is greater than that achieved in fluoride-free serum after 1 and 3 days of immersion.

Tests were carried out to evaluate the effect of the film's stability by immersing the alloy in the serum for 7 days, after which fluoride ions were added (Fig. 8). The EIS diagram obtained after 1 day of immersion in this solution was similar to that obtained for the alloy in fluoride containing serum after $24 \mathrm{~h}$ of exposure. The fitting of the experimental data using the proposed EC revealed unaltered inner layer capacitance and resistance values. However, the outer layer parameters such as the CPE, $\mathrm{n}$ and resistance changed to $9.710^{-6}, 0.91$ and $82 \mathrm{k} \Omega . \mathrm{cm}^{2}$, respectively. Therefore, the

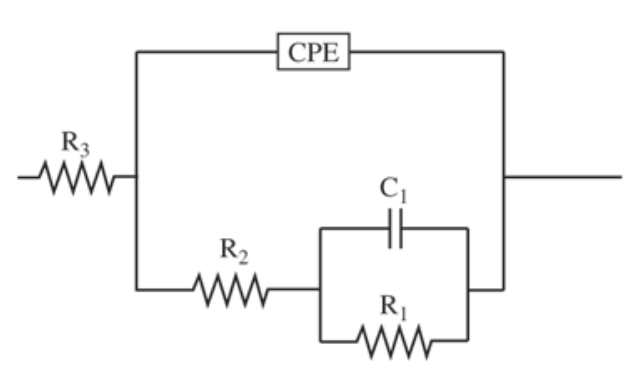

Figure 7. Equivalent circuit obtained from fitting and simulation of Bode plot of Fig. $6 . \mathrm{R}_{3}$ : solution resistance, $\mathrm{R}_{2}$ : outer layer resistance, $\mathrm{CPE}$ : constant phase element, $\mathrm{C}_{1}$ : inner layer capacitance and $\mathrm{R}_{1}$ : inner layer resistance.

Table 4. Fitting parameters used to simulate the EIS plots for Ti6Al4V in lactated Ringer serum.

\begin{tabular}{cccccccc}
\hline Time (day) & Media & $\mathrm{R}_{3}\left(\mathrm{~W} . \mathrm{cm}^{2}\right)$ & $\mathrm{R}_{2}\left(\mathrm{kWcm}^{2}\right)$ & $\mathrm{CPE} 10^{-6}$ & $\mathrm{n}$ & $\mathrm{R}_{1}\left(\mathrm{kWcm}^{2}\right)$ & $\mathrm{C}_{1}\left(\mathrm{mFcm}^{2}\right)$ \\
\hline 1 & Without F & 5.36 & 41.3 & 9.2 & 0.90 & 576 & 22 \\
1 & With F & 3.46 & 100.1 & 1.9 & 0.93 & 318 & 20.7 \\
3 & Without F & 5.86 & 59.4 & 8.3 & 0.90 & 553 & 19.9 \\
3 & With F & 4.03 & 149.6 & 25 & 0.91 & 382 & 53 \\
7 & Without F & 6.56 & 70.4 & 8.5 & 0.91 & 1,020 & 12.5 \\
7 & With F & 3.42 & 52.3 & 21 & 0.93 & 655 & 16.2 \\
\hline
\end{tabular}




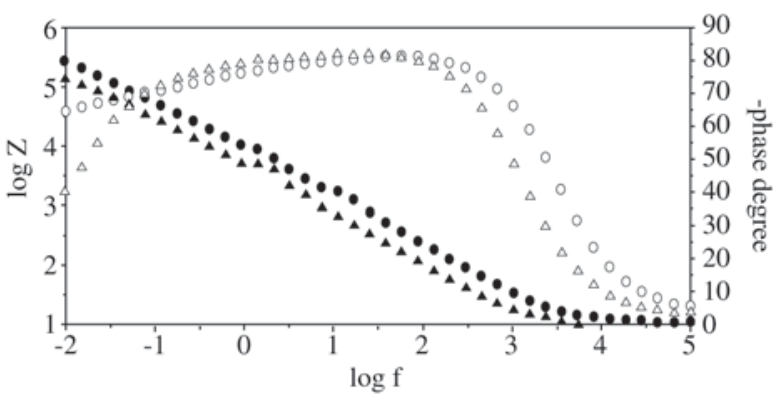

Figure 8. Bode plots obtained for the alloy at OCP; fluoride ions added after 7 days' immersion in the serum $(\bullet)$; fluoride containing serum after 1 day of immersion $(\Delta \triangle)$.

film formed after prolonged immersion in the serum before fluoride ions were added showed higher corrosion resistance and lower porosity, which can be attributed to a porous sealing process that allowed for the film's repair. Possibly, this behavior relates to the formation of a film layer whose thickness offers greater protection of the oxide film. The model described here is in a good agreement with that proposed by Fernandez et al. ${ }^{10}$.

\section{Conclusions}

Ti6Al4V alloy presents OCP values associated with the passive zone after varying immersion times in lactated Ringer's serum, even in the presence of fluoride. Voltammetric studies of the alloy in the serum showed a passive behavior with higher anodic currents in the presence of fluoride. The EIS plots obtained for the alloy after different periods of immersion in the serum indicated an almost capacitive behavior, with enhancement of the film's resistance after 7 days of immersion. The film's resistance decreased in fluoride containing serum, but a stable protective layer was formed after a longer immersion time, a phenomenon that was attributed to a porous sealing process, which allowed for the film's repair. The film formed after prolonged exposure to the serum before the addition of fluoride ions displayed higher corrosion resistance and lower porosity. The results obtained here demonstrate that the behavior of Ti6Al4V in lactated Ringer's serum, $\mathrm{pH}$ 6.5, is passive even in the presence of fluoride.

\section{Acknowledgements}

The authors gratefully acknowledge the financial support of the Brazilian research funding institutions FAPERGS and $\mathrm{CNPq}$ for this work.

\section{References}

1. Raetzer-Sheibe, H.J. Corrosion, v. 34, n. 12,p. 437, 1978.

2. Beck, T.R. J. of Electrochem. Soc., v. 120, n. 10, 1310, 1973.

3. Beck, T.R. ibid, v. 120, n. 10, p. 1317, 1973.

4. Ramires, I.; Guastaldi, A.C. Quím. Nova, v. 25, n. 1, p. 10, 2002.

5. Gonzalez, J.E.G.; Mirza-Rosca, J.C. J. of Electroanal. Chem., v. 471, 109, 1999.

6. Pan, J.; Thierry, D.; Leygraf, C. Electrochim. Acta, v. 41, n. 7/8, p. 1143, 1996.

7. Ciolac, S.; Vasilescu, E.; Morcan, G.; Ivanescu, S. Revista de Chimie, v. 48, n. 9, p. 831, 1997.

8. Yu, S.Y.; Scully, J.R. Corrosion, v. 53, n. 12, p. 965, 1997.

9. Okazaki, Y.; Tateishi, T.; Ito, Y. Materials Trans. Jim., v. 38, n. 1, p. 78, 1997.

10. Fernandez Lorenzo de Mele, M.; Cortizo, M.C. J. of Applied Electrochem., v. 30, p. 95, 2000.

11. Reclaru, L.; Meyer, J.M. Biomaterials, v. 19, n. 1-3, p. 85, 1998.

12. Pourbaix, M. Atlas of Electrochemical Equilibria in Aqueous Solutions, NACE, Houston, p. 213, 1974.

13. Jesuíno, G.A ; Ribeiro, L.M.F.; Nakazato, E. N.; Codaro, L.R. de O Hein Materials Research, v. 4, n. 2, p. 63, 2001.

14. Schiff, N.; Grosgogeat, B.; Lissac, M.; Dalard, F., Biomaterials, v. 23, p. 1995, 2002.

15. Schutz, R.W.; Thomas, D.E. Metals Handbook, v. 13, p. 669, 1987.

16. Kolman, D.G.; Scully, J.R., J. of Electrochem. Soc., v. 140, n. 10, p. 2771, 1993.

17. Kolman, D.G.; Scully, J.R., ibid, v. 141, n. 10, p. 2633 , 1994.

18. Juttner, K., Electrochim. Acta, v. 35, n. 10, p. 1501, 1990.

19. Mansfeld, F., Electrochim. Acta, v. 38, n. 14, p. 1891, 1993.

20. Deflorian, F.; Fedrizi, L.; Locaspi, A; Bonora, P.L., Electrochim. Acta, v. 38, n. 14, p. 1945, 1993. 